\section{DISRUPTION OF THE PELVIS}

\section{A. H. SNOWBALL, M.B., B.S., M.R.C.P.} LATE HOUSE SURGEON, HAMPSTEAD GENERAL HOSPITAL (With Special Plate)

The above term has been used to describe the rare condition of separation of one side of the pelvis from the other, usually as a result of separation of the pubic symphysis, together with separation of the sacro-iliac joint. Peabody, ${ }^{1}$ who reports a series of eight cases, in an extensive search of the literature, only finds sixty-five reported cases in a hundred years. Since then one further case has been reported (Sir W. Wheeler ${ }^{2}$ ).

\section{CASE RECORD}

The following case would seem to present most of the usual features:

The patient, a man of 28 , was admitted to hospital shortly after a fall of some forty feet down a lift shaft on to a concrete floor. He was unconscious, but very restless and somewhat cyanosed. The pulse rate was 92 , but the tension was very poor. There was a fracture of the right tibia and fibula, and measurement (anterior superior spine to internal malleolus) showed nearly half an inch of shortening on that side. However, there was also apparent shortening on the left side, that foot being quite half an inch higher than the right. This was confirmed by taking the umbilicus to internal malleolus measurement, and palpation of the pelvis showed the whole left iliac crest and pubis to be higher than the right. A soft rubber catheter was easily passed, and the urine obtained was clear and contained no blood.

The patient gradually regained consciousness and complained of great pain, especially down the left thigh. The pulse rate rose to 130 , and he vomited considerable quantities of blood mixed with gastric contents. No source of bleeding could be found in the nose or pharynx. A swelling developed in the left loin by the next day, and for a few days the urine contained a little blood, but there was no difficulty or pain on micturition. For several days the patient's general condition was extremely poor, and investigation of his injuries had to be postponed. Some days later $x$-ray examination (see Fig. on Plate) showed a disruption of the pelvis, with separation of the symphysis pubis, and a fracture dislocation of the left sacro-iliac joint, and the whole left innominate bone displaced upwards over half an inch. There was also a fracture through both the pubic and ischial rami on the right side, and a fracture of the tip of the fifth lumbar transverse process on the left side. The right tibia and fibula were fractured.

An attempt was made after some days to reduce the disruption by means of weight extension applied by strapping to the left leg and thigh. This did not have any effect, and so on the twelfth day after the injury the patient was given a general anaesthetic and the displacement reduced by manipulation. A tight bandage was applied round the pelvis, and a weight extension of $20 \mathrm{lb}$. to the left thigh maintained to prevent recurrence of the displacement. The fracture of the right leg was treated by weight extension by means of a Steinmann pin through the os calcis. The patient was kept in bed for four months, and at the end of five months, with the aid of crutches, he was able to get about without pain.

\section{COMmentary}

The condition is generally considered to be due to a severe crushing injury, but several reported cases have been caused by a fall from a height. Separation of the symphysis pubis is not very uncommon, and may occur during childbirth as well as in traumatic cases. On the other hand, the sacro-iliac joint is exceptionally strong and dislocation very rare, owing partly to the strength of the posterior sacro-iliac ligaments and partly to the support, posteriorly, of the posterior part of the iliac crest. Fracture-dislocation may occur, including this posterior portion of the iliac crest. Wakeley ${ }^{3}$ has drawn attention to a bar of thickening in the ilium in the shape of a three-sided pyramid, which both by its thickness and by the arrangement of the bony lamellae adds great strength to the bone. This three-sided pyramid, with its apex to the upper part of the auricular surface and its thickened base to the upper part of the acetabulum, transmits the body weight from the sacrum to the head of the femur. In the case of disruption produced by a fall from a height this thickening in the bone will transmit the force in the opposite direction, and either separation of the sacro-iliac joint or a fracture through its posterior part may occur.

Fracture elsewhere in the pelvic rim is frequently present in this condition, but usually shows little displacement. Fracture of the transverse process of the fifth lumbar vertebra is also not uncommon, and Peabody states that in his series sciatic pain was not a marked feature, except in the cases with this fracture in addition. Two of the most prominent features in the condition are the severity of shock and the rarity of visceral complications. Double dislocation with both innominate bones torn away from the sacrum, as well as separation of the pubic symphysis, has been described ${ }^{4}$ as a result of a severe crushing injury, but resulted in death in a few minutes.

\section{Treatment}

Most of the reported cases have been treated by gradual reduction by means of weight extension. This was attempted in the present case for a few days, but showed no effect. Reduction by means of manipulation under an anaesthetic is usually successful, though often it has to be delayed for some days owing to the degree of shock. Peabody, after fixing the foot of the affected side, tilts the table nearly to the vertical, and then manipulates the pelvis into position under the fluorescent screen. The position is maintained either by plaster or a tight belt, and a weight of $20 \mathrm{lb}$. applied to the limb to preyent recurrence. The eventual result in most of the reported cases is remarkably good.

I am indebted to Mr. WV. H. Ogilvie for permission to publish this case, and to Dr. H. Courtney Gage for the radiograph.

\section{REFERENCES}

${ }^{1}$ Peabody: Arch. of Surg., 1930, xxi, 971.

Wheeler, Sir W. I. de C.: Practitioner, cxxvii, No. 757, 141

${ }^{3}$ Wakeley, C. P. G.: Brit. Journ. Surg., xvii, No. 65, 22.

Warrack: British Medicul Journal, 1908, i, 203.

\section{SPONTANEOUS CURE OF SPINA BIFIDA WITH CONGENITAL DISLOCATION} OF THE LUMBAR SPINE

BY

\author{
DAVID KYLE, M.A., M.B., $\mathrm{C}_{\mathrm{H} . B .}$ \\ GLASGOW \\ (With Special Plate)
}

In this case a girl, now 12 years of age, was found at birth to have a soft swelling over the lumbar spine, which was regarded, and probably correctly, as due to spina bifida. In the course of time the soft swelling disappeared, and is now replaced by a swelling of stony hardness, without the slightest suggestion of any soft place at any part of its surface. The neural canal is now closed completely, but the roof appears to be broader than normal, devoid of spinous processes, and bounded laterally by two osseous ridges, which meet at the upper border of the swelling, but disappear at the lower border, without approaching each other. This bony prominence is roughly circular, with a diameter of about five inches, and is raised fully one inch above the general surface of the body. 


\section{$X$-RAY Findings}

About four months ago the girl was brought to me for an $x$-ray examination. The lateral view of the spine shows the relation of the parts, and a skiagram of the feet demonstrates the associated trophoneurosis in the deformity of the terminal phalanx of the left great toe, with premature union of its epiphysis, and in the outline of the soft tissues. (See figures on Plate.)

The upper portion of the lumbar spine consists of poorly developed vertebrae, and is directed downwards and backwards. The fourth vertebra is better developed, and is directed upwards and backwards, so that its articular surface lies at right angles, instead of being nearly parallel, to the upper portion. The laminae of the third and fourth vertebrae appear to have become united, and thus give some security, but in all probability the chief source of stability is ligamentous union, together with an intervertebral disk on the superior surface of the fourth vertebra. By that means the weight of the body is being transmitted to the pelvis, but on account of the obliquity of the opposing surfaces the weight is borne by the spinal column at considerable mechanical disadvantage, so that part of the weight is tending to increase the deformity.

The antero-posterior view of the spinal column shows a marked scoliosis of both the dorsal and lumbar regions. As one would expect, the lumbar spine shows a greater breadth than normal, but it shows nothing to indicate that the lateral view would reveal such definite evidence of altered structure.

\section{General Clinical Features}

Both lower limbs are remarkably well developed, but the left foot is slightly smaller than the right. There is neither paresis nor wasting of the muscles of the left leg as far as the ankle. Flexion and extension of the left ankle can be performed in a normal fashion, but dorsiflexion of the left toes can be carried out only to a very slight degree; plantar flexion and abduction of these toes cannot be effected at all. The movements of the right foot are normal, and sensation also is normal. There is anaesthesia of the left leg and foot from a line about two fingerbreadths below the knee. This area of anaesthesia corresponds to the segmental cutaneous distribution of the fourth and fifth lumbar and the first sacral nerves. Over this area the patient is unable to feel the prick of a needle, or to distinguish between a test tube of cold water and one of hot water. From time to time the skin on the plantar surface of the left great toe becomes black, and gives rise to a painless ulcer; but at present there is no ulcer, and the only clinical evidence of trophoneurosis is the diminution of the pad of soft tissue on the plantar aspect of the terminal phalanx, and the greatly thickened, hardened, and flattened epidermis. The tip of the left second toe is somewhat reddened, but the skin has never broken down.

In general appearance the girl looks healthy and is well nourished, but as the result of the scoliosis and the lumbar deformity she is only $4 \mathrm{ft} .1 \frac{1}{2} \mathrm{in}$. in height. She is above the average in intelligence, and is a good scholar. She is active on her legs, walks well, and can run about in the usual children's games. She has not had any of the infectious diseases of childhood, nor has she had nocturnal enuresis or any rectal trouble.

\section{Comments}

Because of the condition of her back she was not encouraged to take to her feet early, and did not begin to walk until she was $2 \frac{1}{2}$ years old. At 5 she was fitted with a plaster jacket, which she wore for three years, and after that had a special form of corset, not very stiff, and laced with elastic. This she continued to wear until, as the result of the radiographic findings, she was fitted with a new jacket, of cage-like pattern, constructed with light bars of aluminium, incorporating a crutch under both armpits and a band of aluminium round the upper part of the pelvis, to avoid as far as possible any undue strain on the lumbar dislocation. Dr. John Reid of Forth, Lanarkshire, who had been present at the birth of this girl, states that he remembers her, and " certainly thought that the swelling in the lumbar region when she was born was a spina bifida. It was quite soft."

It appears, therefore, that the nature of the swelling is beyond reasonable doubt, and that it should be regarded as an example of spontaneous cure of a spina bifida associated with congenital dislocation of the lumbar spine. Not all cases of spina bifida are associated with such great alteration in the bodies of the vertebrae. In many, if not in most, the maldevelopment is confined to the neural arch, which makes it all the more remarkable that this case, showing such a gross disturbance of the vertebral bodies, should have undergone a spontaneous cure. That the child is healthy and intelligent, and appears to have a very good prospect of completing the alloted span, is also noteworthy.

For the opportunity of examining and recording this interesting and rare case $\mathrm{I}$ am indebted to Dr. J. N. Jamieson of Kelvinside, Glasgow, and I am grateful to Dr. John Reid for his reply to my query.

\section{REMOVAL OF AN ASCARIS FROM THE COMMON BILE DUCT \\ BY -}

J. B. G. MUIR, M.B., B.S., F.R.C.S.

PRINCIPAL MEDICAL OFFICER, THE KaIlaN MINING aDMINistration, TIENTSIN, NORTH CHINA

(With Special Plate)

Invasion of the biliary tract by parasitic worms is by no means a rare occurrence. A complete Taenia saginata, ten feet long, has been found in the gall-bladder of an old man operated upon for acute cholecystitis (Benedict). It is more usual, however, for the invading worm to be an ascaris, and Aviles has collected ninety reported cases where ascarides have invaded the common bile duct and, in some instances, reached the gall-bladder, a situation where they have been found forming the nuclei of gallstones. Such invasion is usually complicated by impaction of the worms with obstruction of the common duct. Superadded acute infection results, leading eventually to the death of the host, the cause being discovered post mortem. Thus, at a necropsy on a young girl, six abscesses were found on the surface of the liver, each containing a large coiled-up ascaris (Sivasambandan), and, at another on an infant of 11 months, 300 ascarides were counted in the duodenum alone, others being found in the bile ducts and in cavities in the liver (Sinicco). It is rather unusual, however, to detect, at actual operation, an ascaris in the process of invading the gall-bladder, and for this reason I consider the following case worthy of publication.

\section{Case Report}

A Chinese coolie, aged 35, was seized with violent pain in the upper abdomen at $10.30 \mathrm{a} . \mathrm{m}$. on January $3 \mathrm{rd}, 1932$. He collapsed, and was found lying doubled up on his bed with pain. $\mathrm{He}$ was brought to the Tongshan Hospital at 3 p.m. On admission he was in great agony. He had vomited several times, and his pain was localized to the epigastric region. Pulse 100 , temperature $97^{\circ} \mathrm{F}$. There was marked rigidity of the upper abdomen, and tympanites was present, but liver dullness was unimpaired. Slight icterus of the conjunctivae was 


\section{KYLE : SPINA BIFIDA WITH DISLOCATION OF SPINE}

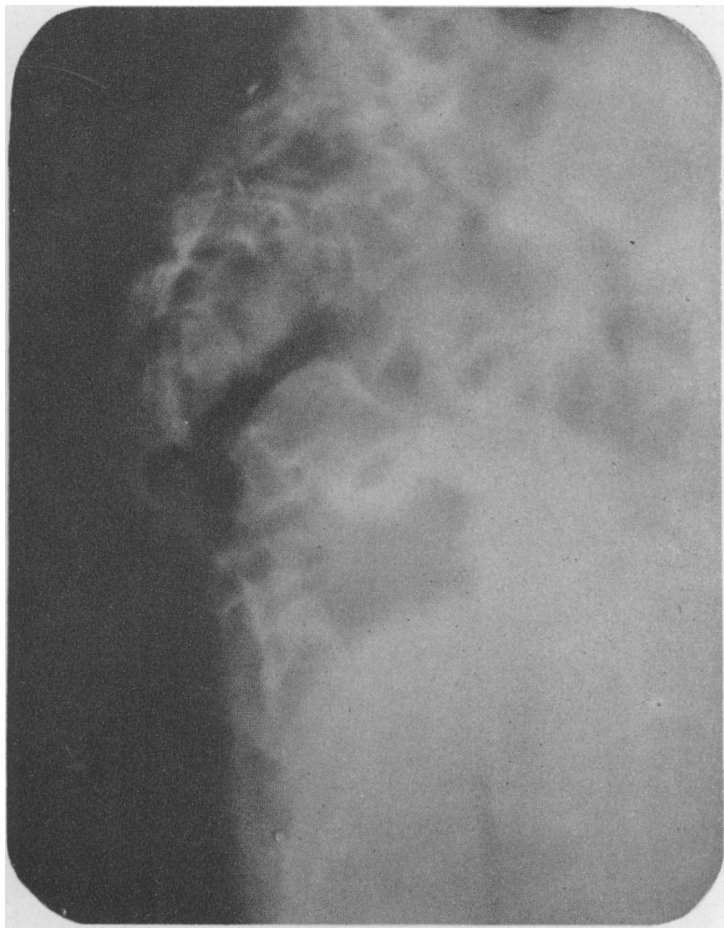

FiG. 1.-Lateral view of lumbar spine (reduced).

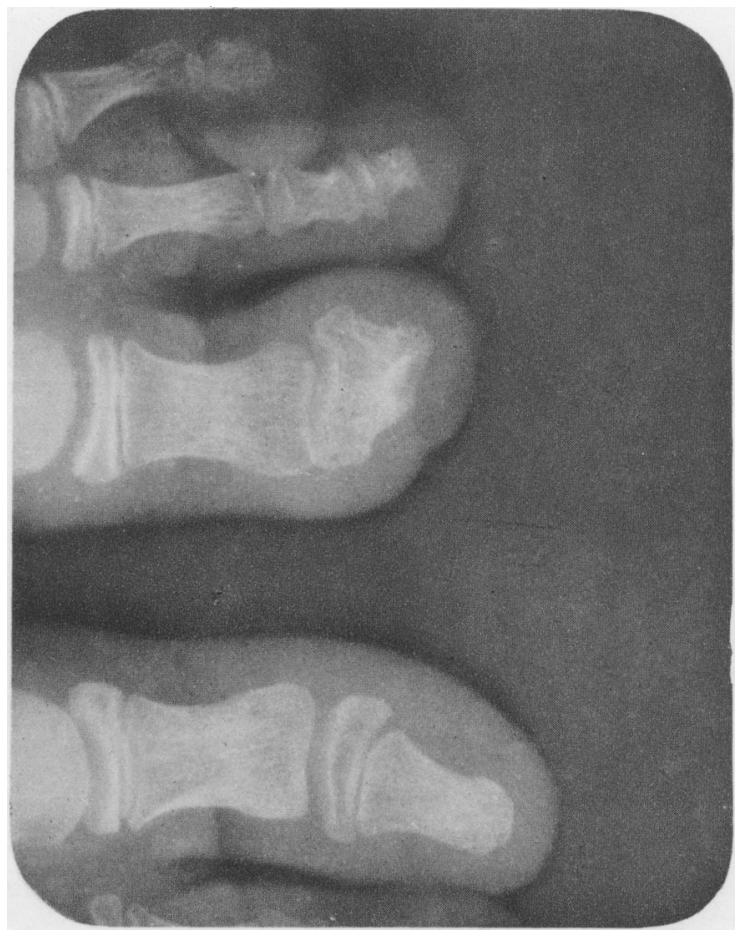

Fia. 8.-Associated trophoneurosis of terminal phalanx of left great toe (antero-posterior view-actual size).
J. B. G. MUIR : REMOVAL OF ASCARIS FROM COMMON BILE DUCT

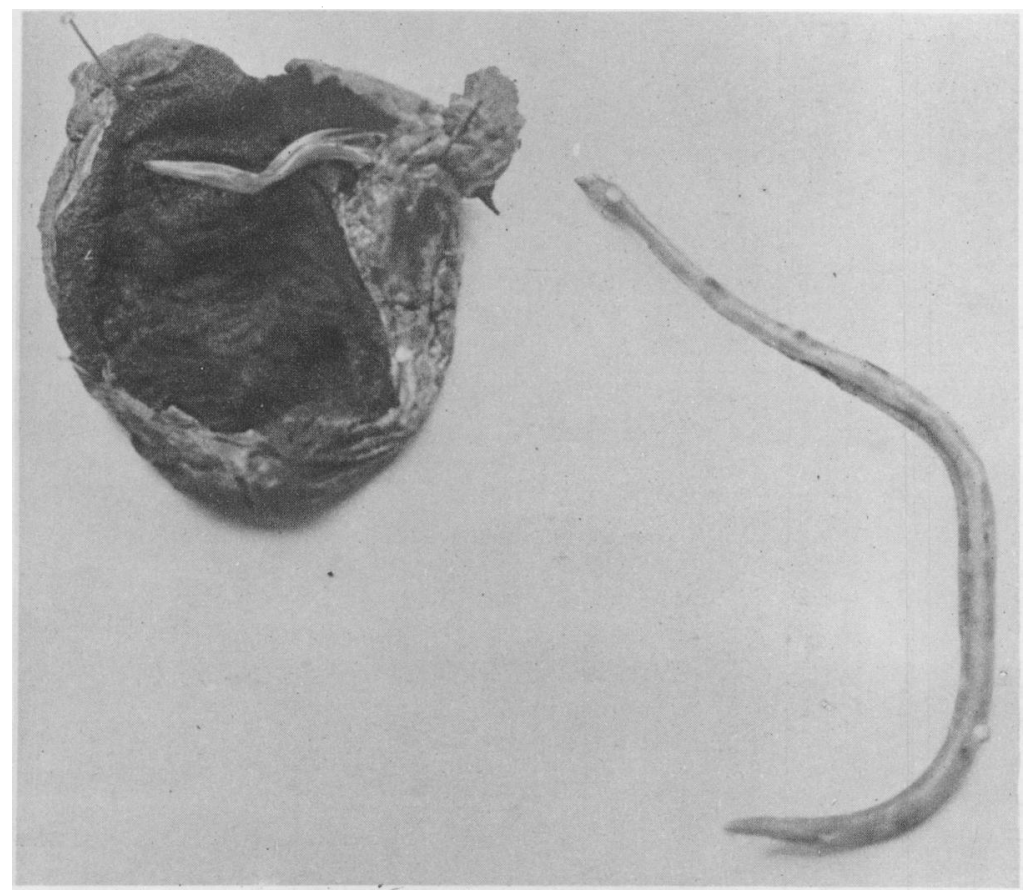

Fia. 1.-Gall-bladder cut open to show proximal portion of worm protruding into lumen. Jistal portion, from common duct, alongside.
G.S. R. LITTLE : UNUSUAL FOREIGN BODY IN FINGER

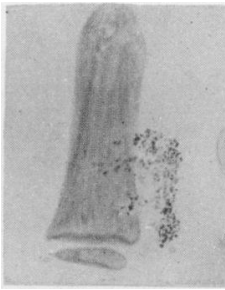

Fig. 1. - Radiograph showing drop-
lets of nercury in area of swelling.

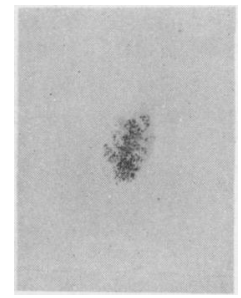

Fra. 2. - Radiograph of flbrous
nodule shrunk down after removal. 